\title{
Political Propaganda, Aesthetics and Sustainable Environment
}

\author{
Ph. D Margaret Olugbemisola Areo
}

Department of Fine and Applied Arts, Ladoke Akintola University of Technology P.M. B. 4000, Ogbomoso, Oyo State; Email: speakwithgbemisola@yahoo.com

\section{Ph. D Adebowale Biodun Areo}

\author{
Department of Management Science, Faculty of Social and Management Sciences \\ Wesley University of Science and Technology, Ondo, Ondo State, Nigeria; Email: talk2areo@yahoo.com
}

Doi:10.5901/ajis.2016.v5n2p9

\begin{abstract}
A significant aspect of political propaganda/marketing often employed by political parties in Nigeria during electioneering campaigns is the printing and pasting of posters in the public built environment. Posters usage as a political party propaganda is a recent development in Nigerian politics. Its evolution is traceable to internal development brought about by emergence of democratic rule in Nigeria and external influence in the introduction of printing into the country. The study therefore examines the impact of propaganda tools such as posters, billboards, banners and flyers on Nigerian-built environment. It aims at identifying the aesthetic and the cost of re-beautification of the defaced environment during electioneering campaign. The study employed the use of qualitative means of gathering and analyzing data, through the use of visual aids. Findings revealed that though posters are cheaper and far reaching especially to advertise middle level politicians, the environments were made unsightly through the indiscriminate pasting of posters and other propaganda tools. It also revealed that the decisions of electorates are not influenced by the use of posters. The paper suggested the proper and decent use of propaganda tools in designated areas and concluded that the environment deserves better handling than what is obtainable currently. The paper therefore, recommends the enactment of environmental laws banning indiscriminate pasting of posters on roundabouts, immovable vehicles, signage, bridges and tarred roads.
\end{abstract}

Keywords: Marketing, Propaganda, Advertising, Aesthetic Built and Sustainable Environments.

\section{Introduction}

Politicians everywhere in the world strive to acquire power to govern people and in doing this they send messages to the electorates through various means. These messages can be found on the internet, especially the social networking blogs such as Facebook and Twitter which post the various electioneering campaigns of candidates. However, journals, periodical, billboards, banners and posters constitutes the print media form of selling candidates to the electorates. This process of selling candidates is termed political marketing; advertising or propaganda. One of the commonest and cheapest means of carrying out political propaganda is the posters.

A poster as a political propaganda tool is a form of advertisement. Advertising being a marketing tool can be traced back to the very beginning of recorded history and according to Dunn and Barban (1978) is as old as man. But modern advertisement in Nigeria started in the early 1960s and 1970s by Rosabel Advertising and Insight Communication. Archaeologists working in the countries around the Mediterranean Sea have dug up signs announcing various events and offers. Kotler and Kelly (2006) define advertising as any paid form of non-personal presentation and promotion of ideas, goods, or services by an identified sponsor.

Propaganda poster is a political advertising tool which enables political candidates to convey their positions on important issues and to familiarize the voters with their personalities. In an environment where a large percentage of the populace still do not have access to television and still move around on their legs without vehicles, the posters become a ready and easy tool of communication. Holsti (1974:212) identifies four elements of propaganda as the communicator, the symbol of persuasion, the media of communication and the target audience. In terms of relationship, propaganda poster satisfies or contains all the elements of this definition.

Propaganda, according to Qualter, 
"is a deliberate attempt by some individuals or groups to form, control, or alter the attitudes of other groups by use of the instrument of communication, with the intention that in any given situation, the reaction of those so influenced will be that desired by the propagandist..." In the phrase, "deliberate attempt" lies the key to the idea of propaganda... Therefore, any act of promotion can be propaganda... when it becomes part of a deliberate campaign to induce action through the control of attitudes (Qualter, 1962:27).

Just as found in advertising, propaganda for distinctly political ends also has a root spanning centuries in history, and the two words, advertising and propaganda, are interchangeably used because they connote the same meaning. In the Holy Bible, Assyrian King, Seninacherib, is recorded to have attempted to terrify the kingdom of Judah to surrender by using threatening propaganda (II Kings 18-19 KJV). (Childs, 2009).

Posters are mass-produced advertisement printed on large sheets of paper for public display, while political advertising is a paid form of mass communication intended to promote the sale of a product, an institution, organization or a political candidate. Propaganda or advertising are part of a larger "marketing mix" which is a set of marketing tools that work together to satisfy customer needs and build customer relationship. Kotler and Gary, (2006), define marketing as the process by which organization create value for customers and build strong relationships in order to capture value from customers in return. From the above, "the twofold goal of marketing is to attract new customers by promising superior value and to keep and grow current customers by delivering satisfaction". This is essentially what posters are set out to achieve in political propaganda. More broadly, marketing offers and also include other entities, such as persons, places, organization, information and ideas.

\subsection{Review of Related Literature}

Poster as a form of political marketing consists of colourful illustration with some texts and according to Encarta (2009), came into existence in the $15^{\text {th }}$ century with the invention of the printing press. Posters did not assume the current modern look until the $19^{\text {th }}$ century due to industrialization, which gave rise to more intensive advertisement and the invention of lithography in 1798. Usage of posters as propaganda tool is recent in the world. In 1824, John Quincy Adams became the first presidential candidate to widely use posters for his campaigns, with the oldest American propaganda poster on record in the Library of Congress digital file being the one used by presidential candidate William Henry Harrison in 1840. (Good, 2011)

Most of the early posters in history, Encarta reiterates, were literal, straightforward and mere text, until 1867 when Jules Cheret began the art of poster designing which was more of illustration and minor explanatory text. This led many painters and artists to try their hands on poster designing. This textual form of early posters according to Good (2011) while quoting Heller was probably because it was harder reproducing images than texts at this time. And also because many people as of this time, were literate and could read the texts. But further into the $19^{\text {th }}$ century, though there were no cameras yet, producing likeness of images in halftones with wood or steel engravings became possible. And by the end of the $19^{\text {th }}$ century, cameras had come into existence. As photography became more widespread, photo production and printing technology evolved and photographs of personalities such as Grant and Abraham Lincoln became accessible.

Encarta (2009) further states that in 1914, during World War I, posters became a propaganda tool for encouraging enlistment into the Army for selling war bonds and by the 1920s and 1930s, posters designing adopted many other styles such as cubism, surrealism, Dada and art décor. And that during World War II (1939-1945), aggressive propaganda posters were produced by major artist such as Russian American Ben Shahir. The post-war posters attracted serious artist and painters such as Pablo Picasso and Salvador Dali. Posters at this period were merely pictorial, carrying artistic or aesthetic messages. Coloured posters did not appear until Richard Nixon campaign for presidency in 1972.

Poster designing is art and an aspect of graphic designing. Poster for propaganda therefore, can be regarded as an art for propaganda which has been defined as:

"Ideological art, executed primarily to persuade the spectator in favour of a literary idea, a philosophical opinion, a religious conviction, a political, social or economic doctrine, or any specific or general course of action. The term is not applied unless the aesthetic merit of the work was, in the mind of the artist, clearly a secondary consideration as contrasted with the propaganda value (Runes and Schrickle, 1946:70)."

From the foregoing, propaganda poster is definitely, a tool for advertising and marketing the political candidates to the electorate. However, the usage of political propaganda posters in llorin is becoming aesthetically offensive to the built environment which has been defined as: 
"buildings, places and structures in which we live, work, and play. It is about the environment that has been created, modified, constructed, developed, and arranged, or maintained by humans, that is, domestic and public buildings, infrastructure, landscaping and other man-made features of our communities. This implies that the built-environment is human environment which include living houses, or residence, erected physical structures, works of art carried out on buildings and the open spaces, parks and gardens and tourist centres, art gallery, museum, symbolic outdoor sculptures, wall paintings and landscaping (Fadare, 2005:132).

However, none of the places mentioned by this definition of what constitutes the built environment is spared from defacing by political propaganda poster.

Designing, printing and pasting of political posters in the public built environment is primarily for propaganda and the aesthetic merit of such posters is secondary and as such, it is an art for propaganda without any consideration for the effect on the environment.

The usage of political propaganda poster in Nigeria is directly linked to the development in the country's politics. Traditionally, in the pre-colonial era, rulership among the Yoruba was not by election, but by heredity within families with royal lineage. This traditional political system still exists, alongside the adopted democratic system, in a large percentage of Yoruba towns with the exception of Ibadan and Abeokuta.(Areo and Areo, 2012). The king known as the Oba held sway. He is the paramount ruler, and is chosen from designated ruling families. Where more than a candidate emerged for the throne, selection of the right candidate was done through consultation of the oracles.

During this early period, all form of advertisement or announcement was done through the town crier who beats the gong in a public square to attract a crowd before making his announcement. Advertisement of products on the other hand was done by hawkers, who, while traversing the length and breadth of the community, carries their wares or goods on their heads and shouts to announce whatever they had for sale. This form of advertisement was later replaced by hawkers on bicycles.

Also in the pre-colonial era, the care of the built environment among the Yoruba was the prerogative of all. According to Adejumo (2005:105):

\footnotetext{
"Members of each compound automatically accepted the responsibility for the upkeep of their immediate environment. Play spaces were swept clean and maintained both within the small family holdings and at the town level... Such public places were kept clean by the entire populace through communal work that was undertaken as often as once a week in some cases (Adejumo, 2005:105).
}

The built-environment therefore, is an expression of the people living within that environment. It expresses their worldview, events in their environment and how they relate to them, and on the whole, their culture, which, in itself, is dynamic. Culture has been defined as the totality of a people's way of life comprising of their collection of shared ideals, values, norms, learned behavioural patterns, attitudes, artifacts, traditions or customs; how they feel and interact; the means by which they order and interpret the world; ways of perceiving, relating and interpreting events based on established social norms Nwosu and Kalu (1923:3). In supporting them, Ogunbameru (2000:50) see culture as a complex whole comprising of a people's beliefs, laws, knowledge, creative inclinations or arts, and any other acquired habits and characteristics.

Poster usage for propaganda purposes is an acquired culture that has become part of our cultural landscape with negative aesthetic impact. Aesthetics is the philosophy that deals with beauty and the beautiful in relation to works of art (Feldman, 1969:43). Since art itself, according to Ducasse (1966:19) and Herskovits (1961:310) is any form of embellishment of ordinary, living which is achieved with skill and has describable form, the built-environment can be considered as one of such activities. This includes the order, maintenance and any additional embellishment of such environments.

The need for political propaganda posters did not arise until the 1950s. Prior to this time, the electoral principle had not been introduced; membership into the legislative bodies in Lagos and Calabar was by nomination and not on political party election basis. It was not until 1957 that other parts of Nigeria experienced electoral principle with representatives into different legislative bodies chosen constitutionally by adopted political parties (Areo and Areo, 2014). At this time, the most prominent propaganda tool was commercial factory printed propaganda cloth first used by Adegoke Adelabu, an Ibadan born civilian. His supporters, in making and wearing dresses made of this material acted as human haulage for his political propaganda message. The novelty and success of Adelabu's propaganda cloth has caught on in Nigerian politics and is now used by political parties and candidates alike as a powerful propaganda tool in addition to posters and many other tools. The emergence of political propaganda posters therefore could not have preceeded this period.

Political propaganda also known as political marketing involves political advertising. It is the use of policies and 
communication to position candidates to gain more votes and sympathy. Harris and Ward (2000) dismissed that political propaganda and the use of political advertisement concepts includes a broader consideration of the needs of the electorate so that policies as well as promotional messages are centered on the desires of voters. The ultimate target of political propaganda is the selling of the candidate, but it has to be achieved through proper positioning and the employment of appropriate strategies and tactics.

According to Ayozie (2011), synergizing political marketing and advertising, means the realized effects of the four elements, that is, marketing, advertising, political philosophy and communications, working together as necessary partners rather than individually.

All forms of political propaganda seek to persuade target audiences by managing the message communicated to them through the media. Political propaganda also seek to communicate their messages via all channels consumed by the target audience or electorates (Egan, 1999; Areo and Eyitayo 2001; Achumba and Ogbechi, 2004), e.g. in newspapers, radio, television, billboards, transportation, handbills, internet and the posters. This paper therefore focuses on posters as a means for political propaganda.

\subsection{Research Problem}

Posters as a propaganda instrument for reaching the electorate have both negative and positive impact on the society. Firstly, the visual impact on the electorate and the effect of getting the message across is undeniable. Secondly, posters have become modern chronicles of Nigerian political history. However, the usage of poster is impacting negatively on the environment. Every four years, the political parties bombard and deface the environment with this propaganda tool without any recourse to the aesthetic value of and unsightly effect on the environment and people they are proposing to rule and protect. These posters remain difficult to remove, half torn, and with the torn ones or its parts littering the areas on which they were pasted during the electioneering campaigns There is a dearth of scholarly work on the impact of posters on the environment and the long-term effect even after the politicians have been elected into their various offices.

This paper, an art historical and marketing research, investigates the provenance of poster usage in Nigeria particularly among its Yoruba speaking populace, with llorin as a case study. It looks into the political paradigm shift that gave rise to its conception, production and the various means employed for its display. The impact of poster as political propaganda on the aesthetic of the environment and the economy, and the effect of its propaganda messages on the electorate is also discussed. Consequently, a paradigm shift in its mode of display is suggested in order to follow political best practices, effect a more acceptable and enduring political culture and a sustainable built environment.

Though there is no available data on the volume of poster usage in Nigeria, in 1998, for instance, more than $\$ 467$ million was spent on election campaign in the USA, placing political advertising among the 30 leading advertisers that year.(Robbs, 2009). This goes to show the cost implication of propaganda posters would have as electioneering tool. However, most of the posters used for electioneering campaign in Nigeria only bear the pictures of the candidates and the party logo. Without any thorough discussion on the issues that pertain to the electorate. Voters are, therefore, bombarded with image advertising rather than cogent issues or the candidates' position on topical issues in the society. Thus, apart from defacing the environment, these posters are harmful to good government and is a distortion of political process, as issues are neglected, while the candidates are 'packaged and sold' much like any other consumer product.

\subsection{Methodology}

The area of study comprises of Ilorin and its adjourning five local government council areas namely, llorin West, llorin East, llorin South, Asa and Moro. Opinion research, according to Ayozie (2011) is more relevant to political propaganda, as such; ad-hoc survey, omnibus project and syndicated projects could be adopted. However, for this study, ad-hoc survey was found to be most appropriate for political marketing.

Two hundred and fifty respondents were selected from the five local government area councils using stratified random and quota sampling methods. Focus group discussion was also adapted to measure public opinion on marketing of aspirants and parties and on the defacing of built environment. The respondents were stratified into male and female, while through quota sampling method, fifty respondents in each local government area were allotted 50 questionnaires. As an ad-hoc survey, simple questionnaires using 5-point Likert scale were used to measure the variables of interest. The questionnaire gave 5-point for Strongly Agree, 4-point for Agree, 3-point for Undecided, 2-point for Disagreed and 1-point for Strongly Disagreed. The findings were analysed using percentages, mean scores, tables and frequency counts. The study was analysed using descriptive method. 
Table 1. Showing level of Agreement of respondents.

\begin{tabular}{|c|c|c|c|c|c|c|c|c|c|c|c|}
\hline \multirow[b]{2}{*}{ VARIABLES } & \multicolumn{4}{|c|}{ Strong Aqree Aqree } & \multicolumn{7}{|c|}{ Undecided Disagreed|Strongly Disagreed|Mean } \\
\hline & $\mathrm{F}$ & $\%$ & $\mathrm{~F}$ & $\%$ & $\mathrm{~F}$ & $\%$ & $\mathrm{~F}$ & $\%$ & $\mathrm{~F}$ & $\%$ & \\
\hline 1.The poster help in your decision to vote. & 70 & 28 & 40 & 16 & 40 & 16 & 60 & 24 & 40 & 16 & 3.763 \\
\hline 2.Your candidates are well known to you. & 80 & 32 & 70 & 28 & 20 & 8 & 60 & 24 & 20 & 8 & 4.412 \\
\hline 3. Poster is the most effective means of politicking. & 40 & 16 & 50 & 20 & 30 & 12 & 80 & 32 & 50 & 20 & 3.083 \\
\hline 4. The messages are easily readable while on motion. & 30 & 12 & 70 & 28 & 15 & 6 & 75 & 30 & 60 & 24 & 2.987 \\
\hline 5. There is aesthetic in the pasting of posters. & 23 & 10 & 47 & 19 & 25 & 10 & 95 & 38 & 60 & 24 & 3.678 \\
\hline 6. The posters are well-placed. & 32 & 13 & 43 & 17 & 44 & 18 & 81 & 32 & 50 & 20 & 2.985 \\
\hline 7. Posters are very necessary no matter the nuisance. & 70 & 28 & 80 & 32 & 10 & 3 & 70 & 28 & 20 & 8 & 3.998 \\
\hline 8. The built-environment is badly affected. & 90 & 36 & 70 & 28 & 15 & 6 & 55 & 22 & 20 & 8 & \\
\hline 9. Rich people and reserved areas seem unaffected by posters. & 71 & 28 & 99 & 40 & 18 & 7 & 52 & 21 & 10 & 3 & \\
\hline 10. Only the low income environments are defaced by posters. & 88 & 35 & 92 & 37 & 10 & 3 & 42 & 17 & 18 & 7 & \\
\hline
\end{tabular}

Source: Survey, 2015.

$\begin{array}{lll}\text { Score: } & = & =\text { High (5) } \\ \text { Strongly Agree } & = & =\text { Above Average (4) } \\ \text { Neither Agree nor Disagree } & =\text { Average (3) } \\ \text { Disagree } & = & =\text { Below average (2) } \\ \text { Strongly Disagree } & = & =\text { Low }(1) \\ \text { Mean score } & = & =3.0 \pm 1.5811 \\ \text { High } & = & =4.5811 \\ \text { Average } & = & =3.000 \\ \text { Low } & = & =1.4189\end{array}$

\section{Findings and Discussion}

Findings in Table 1 show the level of agreement of 250 respondents on the variables bordering on awareness creation through poster propaganda, the effect of indiscriminate pasting of posters on the built-environment. The results in Table 1 reveal that less than average $44 \%$ of the respondents were in agreement that poster usage impact on their decision to vote, while almost an equal percentage $40 \%$ were of the opinion that is expected because estimated $70 \%$ of the electorates for political propaganda had an insignificant impact on their voting.

There were, however, a majority $60 \%$ of respondents who affirm that they could identify their candidates on posters, with $32 \%$ disagreeing. In the focus group discussion, the above claim was corroborated, that although most of the electorate are illiterate, they were able to identify their candidates. The findings further reveal that a small percentage, $36 \%$, were of the view that poster advertisement as propaganda was a highly effective means of selling candidates, but $52 \%$ feel otherwise by disagreeing. They seem to be saying that posters adverts do not matter to them. This idea was further confirmed by the focus group discussion, who claimed that public place campaign to them is more effective.

Table 1, further shows that only $40 \%$ of respondents were in agreement that the messages on the posters were readable and understandable to them. There were, however, over $54 \%$ respondents who disagreed on this claim. This is expected because as said earlier, most of the electorate cannot read and write.

Interestingly, only a minority of the respondents, $29 \%$, agreed that posters on built-environment have aesthetic value, while majority, $62 \%$, disagreed. This implies that majority were not happy about the unsightly manner in which the posters are displayed and the ugly effect it creates when removed after the elections are won and lost .Another majority, $30 \%$, agreed that the posters are properly pasted and on right places. However, a majority, $52 \%$, opined that the posters are ill-placed and are making a mess of the environment.

Table 1, again, shows a majority, $60 \%$, saying, no matter the effect of posters on the aesthetics of the builtenvironment, they are necessary for a good political campaign. In the focus group discussion, most of the discussants were quick to corroborate what the majority said on this. Most of them are of the opinion that after all, this ugliness comes only once in four years. The complainants saying the environment is being made dirty and ugly should bear with them.

There were of majority respondents, $64 \%$, who agreed that the built-environment are badly affected by the propaganda posters, while only $30 \%$ disagreed on this issue. It shows that the electorate was not in support of destroying the built-environment. They added in focus group discussion that government should sanction errant people during any other future elections. 
Another interesting finding was that majority of the respondents, $68 \%$, agreed that only high density areas meant for the low income earners were mostly affected, while the rich people's built-environment is clean and attractive. Focus group discussion revealed that the posters are usually pasted under the cover of darkness; and it is not impossible to wake up and find a wall which the previous night was clean, all covered up with posters of a political candidate or many jostling for placement.

Findings have also shown that posters are pasted majorly in low income areas. In the highbrow areas such as the Government Reserved Area (GRA), which is usually occupied by the rich and influential amongst whom the political candidates are found, the walls are devoid of campaign posters. This probably is due to the security surveillance provided by the presence of security personnel and dogs in such residences.

Also the posters are pasted under the cover of the dark at night and with such a strong adhesive as to deter their removal by opposing parties. New ones are therefore super imposed on the old posters, and when attempts are made to forcefully remove them, unsightly patches of irremovable paper are left.

It was further observed that it is not only walls that are covered, any flat surface or standing object or form is defaced; refuse bins, water tanks, walls, bus stations, kiosks, traffic warden stands, pavements, roundabouts, and sculptural works were massively defaced and their aesthetics destroyed.

\section{Summary and Conclusion}

Intense competition surrounding the election and the ultimate desire to be absolute winner creates a highly charged and negative form of campaigning usually heightened by the indiscriminate use of posters. This situation often leads to scuffles and disturbance of law and order between rival party agents. Although political propaganda or marketing was able to showcase and position the electorate to some extent, the negative aspect of these posters before and after election to the built environment was adjudged by the majority of respondents as bad and embarrassing to the tourists and tourism development.

Advertising in advanced countries, is subject to both government regulation and industry self-regulation to prevent deceptive advertising and limit the visibility of advertising. In the USA, Federal, State and City governments have passed legislation to restrict advertisements. State laws and enforcement bureaus impose additional regulation on certain types of advertising especially those involving contests. And in certain States' outdoor billboard are banned out rightly.

In Nigeria, there is the Advertising Practitioners Council of Nigeria (APCON), which is a body to regulate and standardize advertising practice. This body, however, does not seem to be doing much in regulating how propaganda posters printed by their members are posted. There is an urgent need to evolve a policy that will restrict where and how posters are pasted in the built-environment.

The ugly situation found before, during and after political elections leaves much to be desired. It is an assault on the built-environment and a defacement of our culture, a part of which our environment is as we know it. Any visitor to the environment before, during and long after an election, is bound to go away with an impression of a culturally-ugly builtenvironment.

Furthermore, the environment is a cultural legacy we are leaving to the upcoming generations. If they do not know how an aesthetically pleasing environment should look like, the future generations are likely to perpetuate the ill that they are seeing now as the norm.

Sustainable development has been defined as "development that meets the needs of the present generation without compromising the ability of the future generation to meet their needs (World Commission, 1987). For the future generation to be able to meet their culturally-aesthetic environment there is a need to stop the ugly trend being created in the built-environment by political propaganda posters.

There is no gainsaying that democratic election as a means of choosing leaders in Nigeria has come to stay. The culture, though borrowed from the Western world, is being appreciated day-by-day. However, the appreciation and acceptance come with a negative price. This price is that, at every four years, the built-environments are destroyed, defaced and messed up by indiscriminate pasting of posters without any plan to restore the environmental aesthetics after the elections.

To any tourist coming to cities like llorin, he may adjudge the city as being peaceful, but not clean, as a result of these political propaganda posters. It is instructive that the electorate was also not happy at the destruction of aesthetics of the built-environment when the political candidates are being .marketed. The aftermath of these elections is an untidy, filthy and unsightly environment, with the buildings, immovable objects such as broken down vehicles, signposts, road signage, roundabout railings and bus-stops defaced with propaganda posters. 
Majority of the respondents want government to take drastic measures to forestall future occurrences. It was observed that most of the posters were clandestinely placed when law enforcement agents were asleep and therefore not on duty. The respondents further add from the findings that posters had little influence on their voting pattern as most of the candidates lived in their midst and were already known to them before the election.

Conclusively, the respondents would wish that the political candidates use other means of marketing themselves. The pasting or arrangement of the posters should be regulated and mounted in an orderly manner. As it were the mounting of posters on valuables such as cars water tankers, bus-stops and walls of homes create unsightly builtenvironment that is abhorring and condemnable. The governments, both at Federal, State and Local Government levels, should come out with a policy to regulate pasting of posters in the built-environment. Also, our architects, urban and regional planners, and artists should work together in advising the government on a sustainable environment. In line with the thought of this study, Nzimiro(1992) was of the view that political propaganda or advertising should be a tool for pointing out the dangers of ethnicity in politics and ensuring the beautification of built environments.

\section{Recommendations}

Federal, States and Local Governments should put in place laws which would regulate the use of posters for political propaganda. There should be heavy sanctions for errant candidates and their agents. There should be awareness creation towards making the built-environment clean and not destroyed during political campaigns.

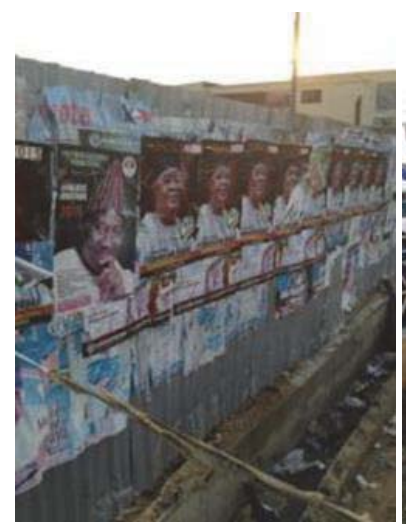

Plate 1a

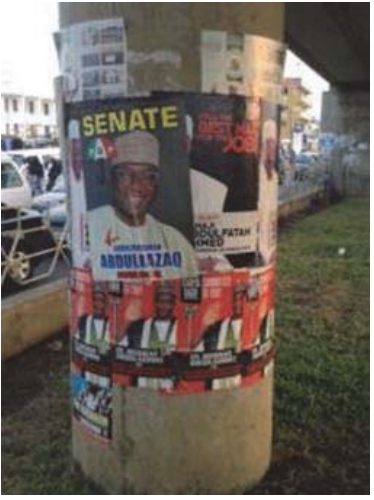

Plate 1b

Plates 1a \&1b: Corrugated Alluminiun Sheet Fence \& Pillar of Overhead Bridge covered with posters. Ilorin. Photograph by Debo Areo. 2015

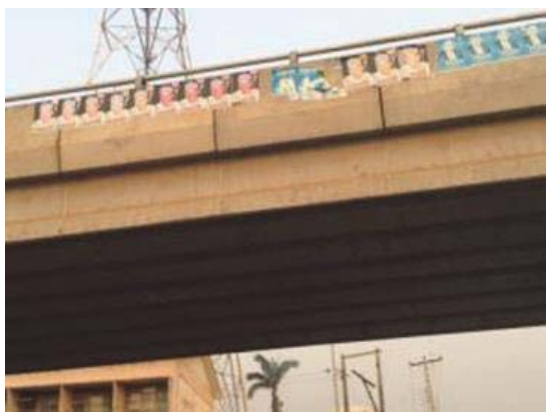

Plate 2a

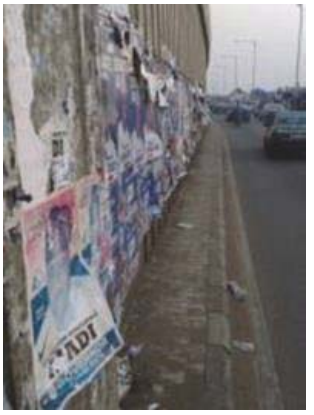

Plate 2b

Plate 2a \&2b: Overhaed Bridge \& Side of Bridge covered with posters. Ilorin. Photograph by Debo Areo. 2015 


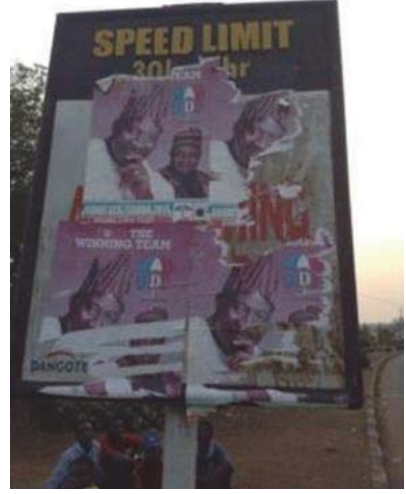

Plate 3a

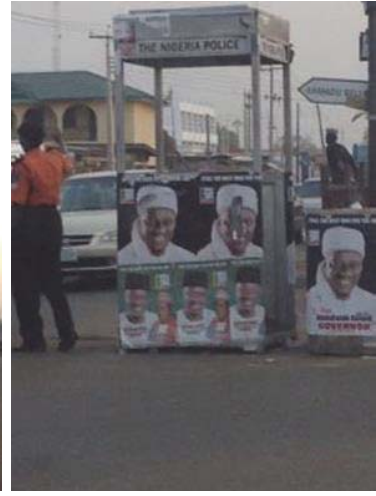

Plate 3b

Plate 3a \& 3b: Speed Limit Signage \& Traffic Warden Booth covered with posters. Ilorin. Photograph by Gbemi Areo. 2015

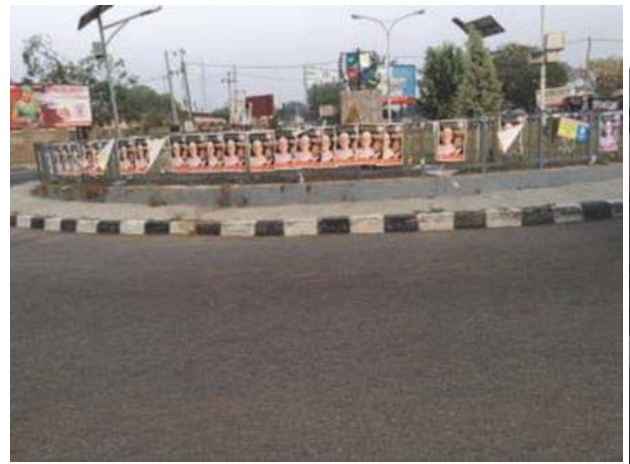

Plate 4a

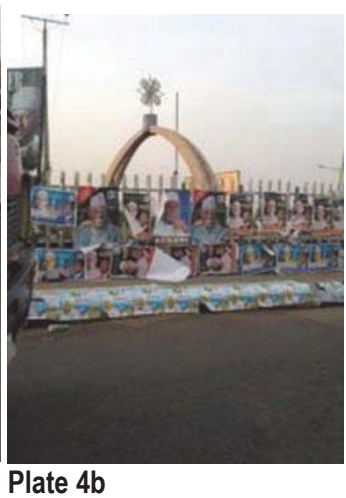

Plate 4b

Plate 4a \& 4b: Two different round abouts covered with posters. Ilorin. Photograph by Gbemi Areo. 2015

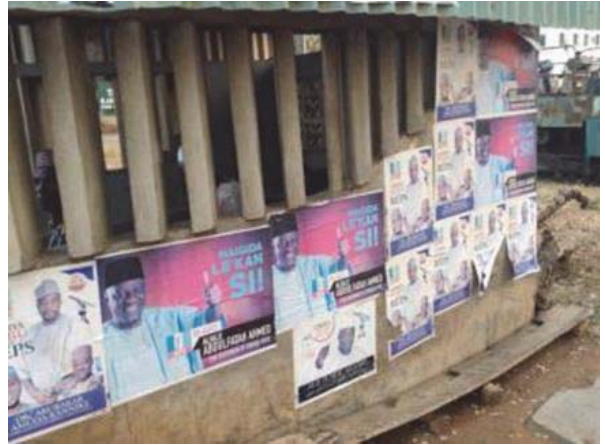

Plate 5a

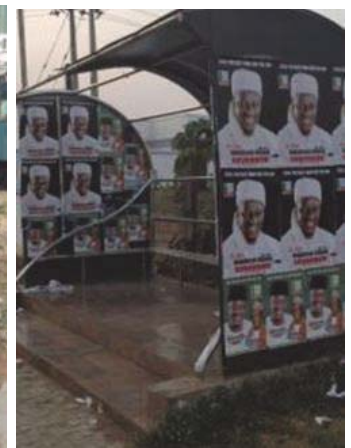

Plate 5b

Plate 5a \& 5b: Two different bus stations covered with posters. Ilorin. Photograph by Debo Areo. 2015 


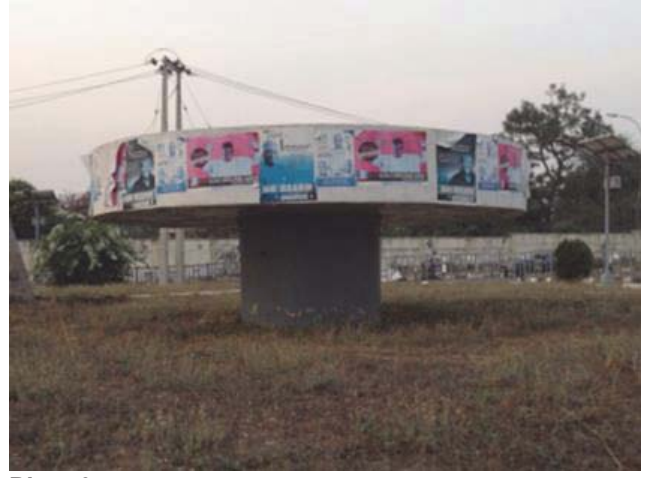

Plate 6a

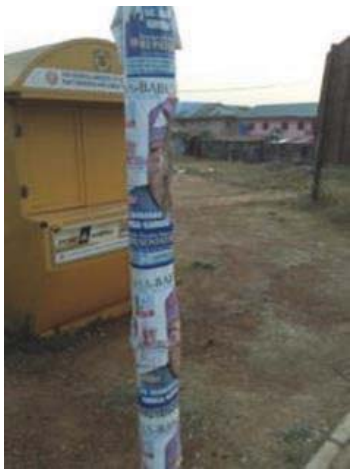

Plate 6b

Plate 6a \& 6b: Monument ana lamp post covered with Posters. Ilorin. Photograph by Debo Areo. 2015

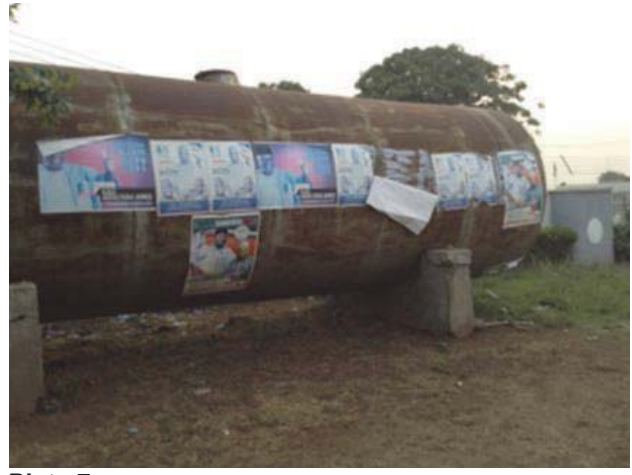

Plate 7a

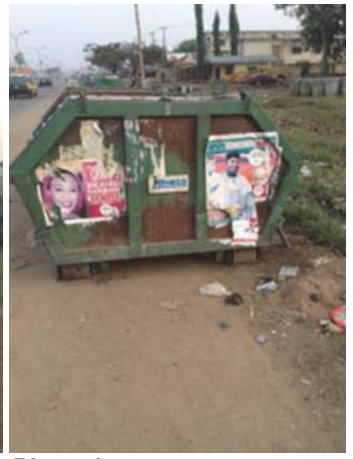

Plate $7 \mathrm{~b}$

Plate 7a \& 7b: Water Tank and Refuse Bin covered by posters. Ilorin. Photograph by Gbemi Areo

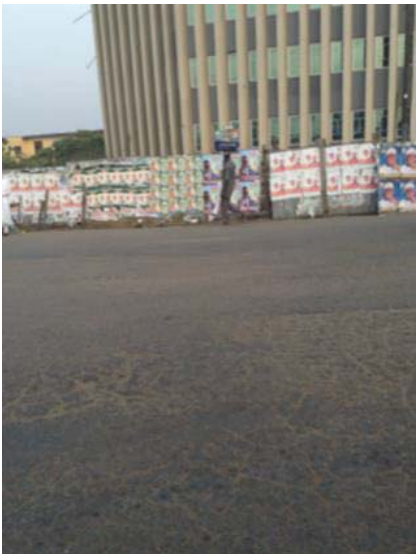

Plate 8a

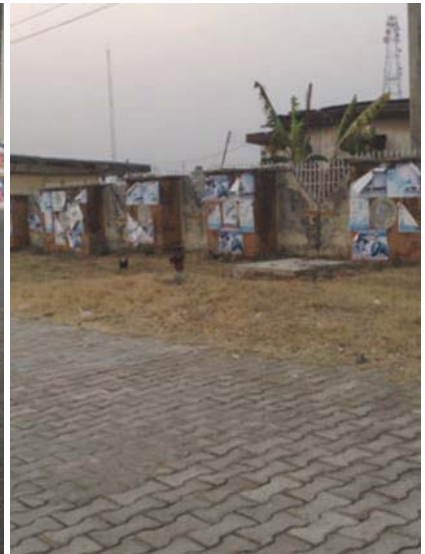

Plate 8b

Plate 8a \& 8b: Fences of Public buildinds covered with posters. Ilorin. 2015 Photograph by Debo Areo 


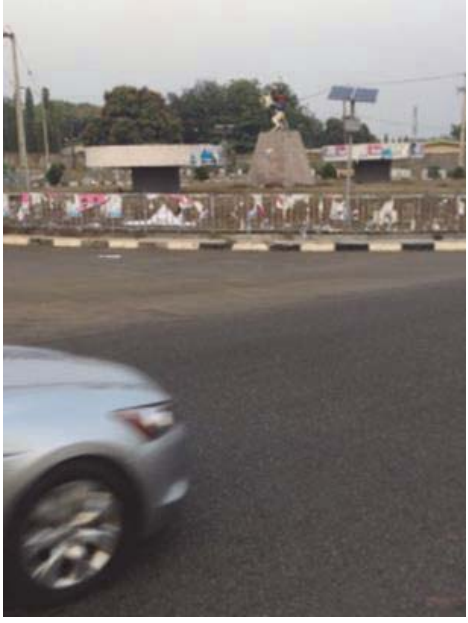

Plate 9a

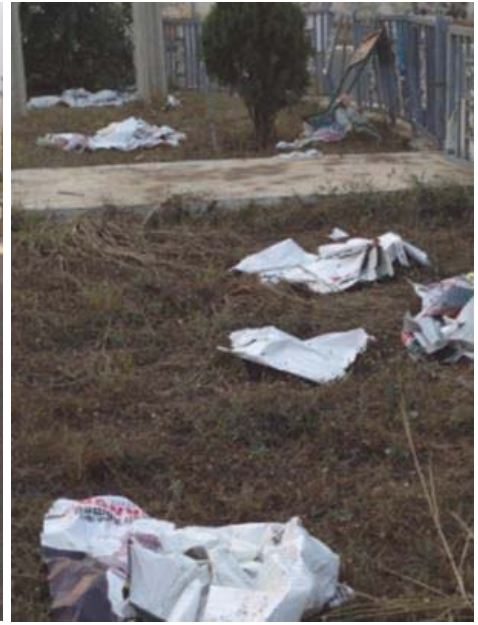

Plate $9 b$

Plate 9a \& 9b: Aftermath of poster removal. Ilorin. 2015. Photograph by Gbemi Areo

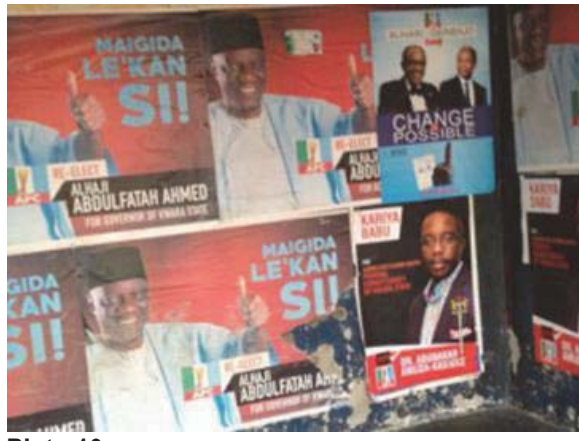

Plate 10a

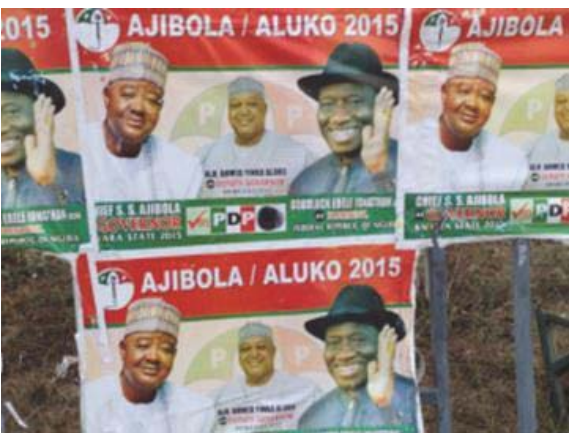

Plate 10b

Plate 10a \& 10b: Posters bearing pictures and names of candidates without addressing societal isssues. Ilorin. 2015. Photograph by Gbemi Areo

\section{References}

Aaron, G. (1992). Promoting politicians: political science perspectives in marketing polices, APCON, Nigeria.

Achumba, I.C.; Ogbechi, D.; and Bolajoko, N. (2004). Political marketing, marketing unusual. Marketing Journal. No. 1, Quarterly publication of the National institute of marketing of Nigeria, Lagos, Nigeria.

Adejumo, A. (2005). Globalization and the beauty of the Nigerian-built environment". In Conference proceedings on Globalization, culture and the Nigerian Built Environment. Vol. II (Fadare, et al. ed.), Ile-Ife, O.A.U.

Agbakoba, M. (1992). Promoting politicians, consumer marketing perspectives. In Marketing politics. APCON, Lagos, Nigeria.

Areo, A. and S. Eyitayo (2001) Principles and practice of marketing. Nigeria: Swift Prints Publ. Inc.

Areo, M.O. and Areo A. "Textiles, political propaganda and the economic implication in Southwestern Nigeria" Textiles and Politics: $13^{\text {th }}$ Biennial Symposium of Textile Society of America. September 19 - 22, 2012, Washington, D.C.

Ayozie, D.O. (2005). Planning public relations' functions. The Chartered Marketer NIMN journal, Lagos, Nigeria.

Ayozie, D.O. (2011) The use of Marketing and advertising strategies in political marketing. The Nigerian Accountant, Vol.44, No.2 April/June. The Official journal of the Institute of Chartered Accountants of Nigeria.

Childs, H.L.(2009).Propaganda. Microsoft Encarta (DVD) Richmond, W.A: Microsoft Corporation, 2008.

Dunn, W. and Barban, A. (1978). Advertising: Its role in modern marketing (2nd ed.). Illinois: The Dryden Press. Rinehart and Winston Publishers. 
Egan, J. (1999). Political marketing. Lessons from the Mainstream Conference. University of Sterling, UK.

Fadare, M.O. (2005). Issues, challenges and benefits of globalization to visual arts and the Nigerian Built Environment. In Conference proceedings on Globalization, Culture and the Nigerian Built Environment. Vol. II (Fadare et al. eds), Ile-Ife, O.A.U.

Feldman, J.K. (1969). Aesthetics. New York: Humanities Press. Good, C, (2011). The Evolution of the Campaign Poster. The Atlantics Virginia-Miller Centre.org/ President/ University/University jqadams/essays/bibliography.

Harskovits, L. 91961). The aesthetics drive: graphic and plastic arts. In Man and his works. New York: Alfred

Knopf. Nwosu, H.N. and Kalu, O.U. (1980). The study of African culture, African cultural development. Kalu O.U. (edited), University of Nigeria, Nsukka.

Ogunbameru, O.A. (2000). Culture: the fabric of human society. In Man and his social environment. Ogunbameru, O.A. and Rotimi R.A.(eds): Cardinal Crest Limited, Ibadan.

Kotler, P. (1991). Marketing management analysis, planning, implementation and control. Englewood Cliffs, New Jersey, Prentice Hall Inc., USA.

Kotler, P and G. Armstrong (2006). Principles of marketing. 11 th edition.

Kotler, P. and Keller, K.L. (2006) Marketing Management. Delhi, India: Prentice Hall of India Private Limited.

Nzimiro, I. (1992). Critical issues in political advertising in marketing politics. In Advertising Strategies and Tactics, by Advertising Practitioners Council of Nigeria, Lagos, Nigeria.

Qualter, T.H. (1962). Propaganda and psychological warfare. New York. Random House.

World Commission on Environment and Development (1987). Our common future. London: Oxford Press.

Robbs, Brett (2009) Advertising. Microsoft Encarta (DVD), Richmond, W.A: Microsoft Corporation 2008. 
